\title{
Detection of Plausible Radial Growth Scenarios for Pinus sylvestris L. Responding to the Climate Change at the North of the East European Plain
}

\author{
Denis Tishin* and Nelli Chizhikova
}

Department of General Ecology, Institute of Ecology and Geography, Kazan Federal University, ulitsa Kremlevskaya, dom 18, Kazan, 420008, Russia

\begin{abstract}
The results of analysis of tree-ring growth for Scots pine from islands of Ketersky archipelago in The White Sea, Russia are presented. Two tendencies were found for pine radial growth: a positive response to spring warming and a negative one to the increase of winter precipitation. The link between radial growth and climatic variables changes over time, which is due to regional climatic shifts. The complex impact of climatic factors on radial growth was evaluated through decision trees (CART). This integrated approach allowed to propose three scenarios leading to increased, moderate and lowered radial growth. The detected relationships can be used in further investigations of three growth and adaptations in relation to the climate change.
\end{abstract}

Keywords: Climate, radial growth, Scots pine, tree rings.

\section{INTRODUCTION}

The results of analysis of tree-ring growth of Scots pine from Keretsky archipelago are presented (N66 $20^{\prime} \mathrm{E} 33^{\circ} 49^{\prime}$, Fig. 1). The main goals of the study were (i) to depict climatic variables and their possible superposition, which influence radial growth rate; (ii) to look for evidences of the climate change and its effect on tree-ring growth.

Two chronologies were analyzed: from a dry pine forest (10 tree-cores used) and from a bog habitat (6 cores). The number of trees was limited due to the sampling strategy: the oldest (the biggest) upright standing trees without signs of injury were selected for research. Tree cores were measured using LINTAB system and TSAP-Win software. Chronologies were characterized by a ring width index (RWI) calculated as the pre-whitened mean of a detrended individual tree-ring series. Detrending was done by dividing of each raw individual tree-series by a $67 \%$ smoothing spline with a 50\% cutoff. The resulting final chronology was derived as the mean of an individual series whitened by extracting of the residuals of the modeled autoregressive process. The order of autocorrelation for each series was determined using Akaike information criteria [1]. RWI was calculated using dplR package in R environment [2-4].

The daily mean temperature and summary precipitation were obtained from the nearest weather station Umba (http://climexp.knmi.nl, Fig. 1). These data were used to construct a broad set of climatic variables: 10 day mean temperature and 10 day summary precipitation; mean monthly temperature and summary monthly precipitation;

*Address correspondence to this author at the Department of General Ecology, Institute of Ecology and Geography, Kazan Federal University, ulitsa Kremlevskaya, dom 18, Kazan, 420008, Russia; Tel: +79033871574; Fax:+7(843)2337417; E-mails: dtishin@kpfu.ru, dtishin80@gmail.com count of days with temperature higher than $5^{\circ} \mathrm{C}$; mean temperature and summary precipitation for spring, summer and winter. The time span of variables covers the period from March of the previous vegetation season to September of the current vegetation season.

The earliest year of climatic records is 1937. Age of the cored trees is around 300 years. These facts mean that all found relationships between tree radial growth and climate impact describe rather mature pine trees resistant to unfavorable conditions.

\section{DRY PINE FOREST}

A positive response of RWI to spring season warming and summer temperature was detected for the whole investigated time span (1937-2009). The only statistically significant $(p$-value $<0.01)$ correlation coefficients were considerably small: 0.34 for the mean temperature of AprilMay, 0.33 for spring mean temperature, 0.33 for mean temperature of July and 0.32 for summer mean temperature.

The studied data were splitted onto two time subsets: 1937-1971 and 1972-2009 in order to analyze if there are any changes of the growth-climate relationship. The 19371971 time subset showed nearly the same combination of correlations with the climate variables: 0.49 for mean temperature of the April-May span, 0.43 for spring mean temperature, 0.46 for mean temperature of July and 0.47 for summer mean temperature. The new climate variable became statistically significant for this time span: $R=0.47$ (p-value $<0.01)$ between RWI and mean temperature of March.

The second 1972-2009 time subset shows a changed pattern of relationship. The only significant correlation of radial growth can be observed with summary precipitation of 


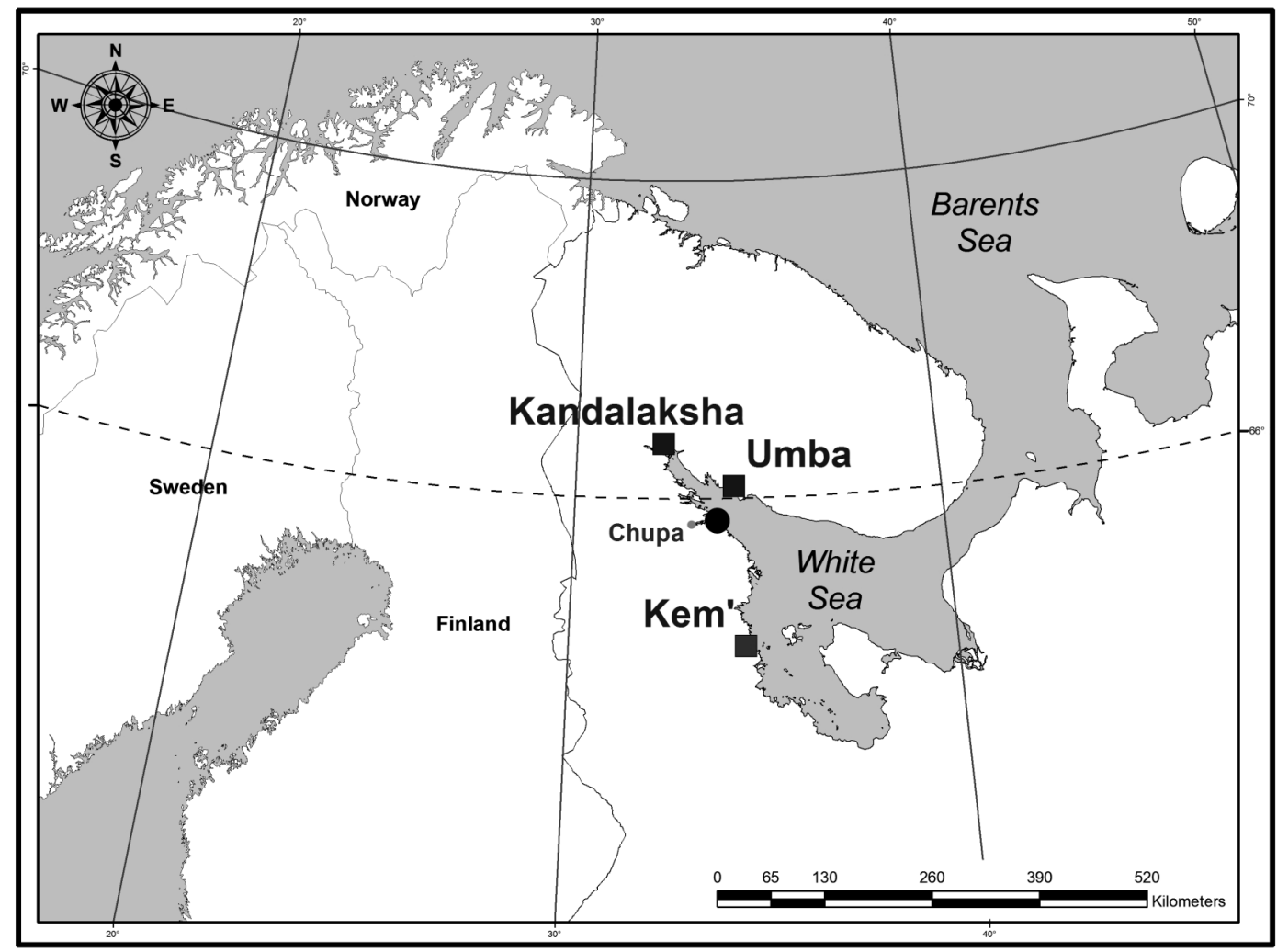

Fig. (1). Map of Keretsky archipelago. Black dot near Chupa village denotes site under study. Black squares (Umba, Kandalaksha, Kem') corresponds to the nearest weather stations.

the late February $(\mathrm{R}=-0.45$, $\mathrm{p}$-value $<0.01)$. Changing of the link between radial growth and climatic variables can be attributed to the regional climatic shifts: increased amount of annual precipitation (rate is $1.5 \mathrm{~mm}$ per year, $\mathrm{p}$-value $=0.05$ ) and increased annual mean temperature $\left(0.02^{\circ} \mathrm{C}\right.$ per year, $\mathrm{p}$ value $=0.05$ ).

\section{BOG PINE FOREST}

Two correlation coefficients between RWI and climatic variables were statistically significant: 0.32 with mean temperature of late June $(\mathrm{p}$-value $<0.01)$ and 0.32 with mean summer temperature ( $\mathrm{p}$-value $<0.01$ ).

Splitting of data into two time subsets did not reveal any change of the RWI-climate relationship pattern.

\section{GROWTH SCENARIOS}

A complex impact of climatic factors on radial growth was evaluated by descision trees (CART) [5, 6], which can be expressed as a set of rules juxtaposing combination of climate variables with RWI. Each RWI chronology was classified in an ordinal variable coded as "lowered" (code 1), "moderate" (code 2) and "increased" (code 3) radial growth. Due to data limitation it was decided to restrict the computational algorithm to the simple tree structure of 3 nodes. Resulting models for bog and dry forest are presented in Fig. (2) and Fig. (3) correspondingly.

Both bog and dry forest pines respond negatively to the increase of snow precipitation in mid and late March (corresponding mean temperatures $-7.9^{\circ} \mathrm{C}$ and $-5.4^{\circ} \mathrm{C}$ ). It can be supposed that the increase of the snow cover shifts the start of vegetation and leads to narrower rings. The amount of snow precipitation can be compensated by spring and summer temperatures. Dry forest pines tend to react to the mean spring temperature (April-May) in comparison with bog pines, positively associated with summer temperature. One of the possible reasons of this difference can be inertia of the bog habitat and late start of cambial activity.

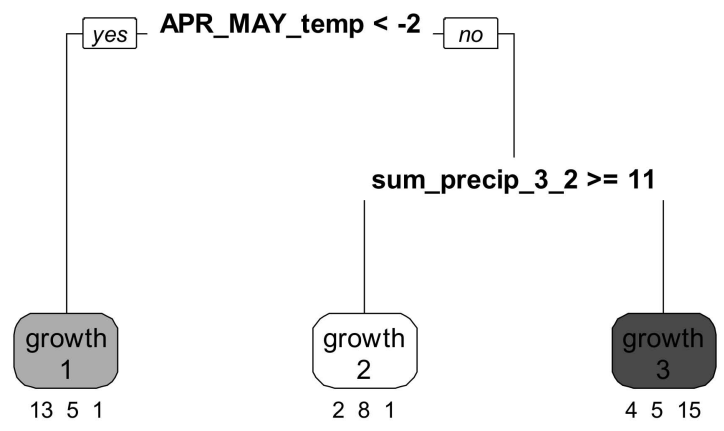

Fig. (2). Classification tree for the dry pine forest chronology. Abbreviations: APR_MAY_temp - mean temperature of April and May; sum_precip_3_3 - summary precipitation of late March.

This report is a pilot study for this locality. Detected relationships can be used in further investigations of tree growth and adaptations in relation to the climate change. The research in Keretsky archipelago is continued and new treecores are obtained. In 2013 air thermometers and precipitation gauge were installed to gain more specific 
information about weather during the vegetation season. New data permit to examine consistency of the outcomes made in this report. Due to the complex nature of relationship between tree radial growth and numerous correlated habitat factors, multimodel inference approach [7] or Random Forest algorithm [8] could be proposed to detect important variables influencing tree radial growth.

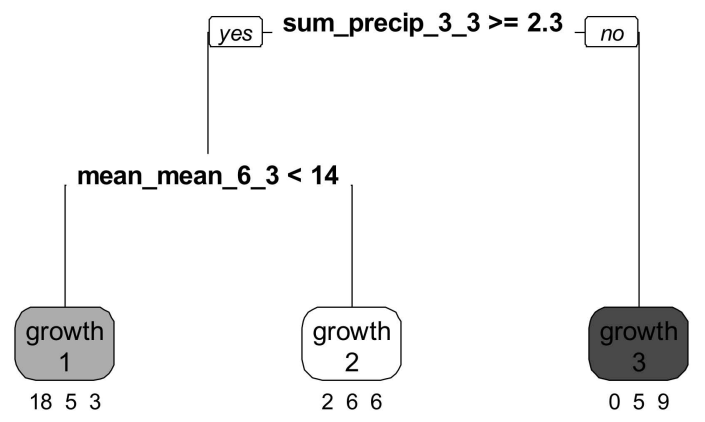

Fig. (3). Classification tree for the bog pine forest chronology. Abbreviations: sum_precip_3_3 - summary precipitation of late March; mean_mean_6_3 - mean temperature of late June.

\section{CONFLICT OF INTEREST}

The authors confirm that this article content has no conflict of interest.

\section{ACKNOWLEDGEMENTS}

The study was partly supported by grant no. 12-04-31449 of Russian Fund for Basic Research.

\section{REFERENCES}

[1] Akaike H. A new look at the statistical model identification. IEEE Trans Automat Contr 1974; 19 (6): 716-723.

[2] Bunn AG. A dendrochronology program library in R (dplR). Dendrochronologia (Verona) 2008; 26: 115-124.

[3] Bunn AG, Korpela M, Biondi B, et al. dplR: Dendrochronology Program Library in R. R package version 1.5.6. 2012 [Cited 2013 Mar 10]. Available from: http://CRAN.R-project.org/package=dplR

[4] R Core Team. R: A language and environment for statistical computing. Vienna, Austria: R Foundation for Statistical Computing; 2012 [Cited 2013 Mar 10]. Available from: http://www.R-project.org/

[5] Breiman L, Friedman JH, Olshen RA, Stone CJ. Classification and Regression Trees. Monterey, CA: Wadsworth and Brooks; 1984.

[6] Therneau T, Atkinson B, Ripley B. rpart: Recursive Partitioning. R package version 4.1-0. 2012 [Cited 2013 Mar 10]. Available from: http://CRAN.R-project.org/package=rpart

[7] Burnham KP, Anderson DR. Model Selection and Multimodel Inference: A Practical Information-Theoretical Approach. 2nd ed. New York: Springer-Verlag 2002.

[8] Breiman L. Random Forests. Mach Learn 2001; 45 (1): 5-32.

Received: March 15, 2013

Revised: March 15, 2013

Accepted: October 31, 2013

(C) Tishin and Chizhikova; Licensee Bentham Open.

This is an open access article licensed under the terms of the Creative Commons Attribution Non-Commercial License (http://creativecommons.org/licenses/by$\mathrm{nc} / 3.0 /$ ) which permits unrestricted, non-commercial use, distribution and reproduction in any medium, provided the work is properly cited. 